\title{
The Achievement Gap between Science Classrooms and Historic Inequalities
}

\author{
Sarah Howie \& Vanessa Scherman
}

\begin{abstract}
In the past politics deprived many African children (in particular) in South Africa the opportunity of achieving quality education. This was most especially true in subjects such as mathematics and science. In this research the science teacher-level data from Third International Mathematics and Science Study 1999 (TIMSS'99) were analysed with a view to evaluating the politicized gap between what are viewed as well-functioning and provisioned classrooms (predominantly housing White teachers and White or mixed classes in urban areas) and not well-functioning and poorly provisioned classrooms (largely African teachers and African pupils in peri-urban and rural areas). The data are explored in this article to ascertain and gain insight into similarities and differences in classroom conditions, teacher actions and the relationship between these and pupils' achievement in science in South African classrooms. Significant differences in achievement were found between classrooms headed by teachers with different racial profiles, where the pupils' average class science score taught by White teachers was about 300 points more (on a scale with an international mean score of 500 points) than children taught in classrooms by African teachers. Furthermore, the average class science score in rural areas was about 130 points below classes in urban areas. These blatant inequalities contribute to what is believed to be an increasing gap in achievement in science. Whilst these results are not altogether unexpected, there were some interesting results in terms of possible explanatory factors for the gaps in achievement which have ramifications for policymakers.
\end{abstract}

\section{Introduction}

This paper aims to ascertain the extent of the gap existing between classes of different schools regarding classroom conditions, teacher characteristics and teacher actions in South Africa and secondly to determine the extent to which a variation in conditions and teacher actions is related to the achievement in science in South African classrooms. South Africa is described as being both first world and third world in nature and as such this gives rise to differences in conditions and performance nationally.

In the past politics deprived many African children (in particular) in South Africa the opportunity of achieving quality education. This was most especially true in subjects such as mathematics and science where very few African pupils exited school with qualifications in science. The actions of politicians in the mid-1900s, to systemically prevent good quality education for children of the so-called nonWhite ${ }^{1}$ communities, has had a devastating impact, most especially on the mathematics and science education, some 50 years later. Some sense of these

\footnotetext{
${ }^{1}$ This term used during the Apartheid era denoted any person of colour as being non-European whilst the term White indicated a person of European descent.
} 
actions causing a huge racial divide can be detected in Table 1 [at end of article].

The design and implementation of interventions to restore quality education is currently a priority within South Africa. This has not been without its own controversies (such as the new Curriculum $2005^{2}$ multilingual education, redeployment of teachers and several others). Just as a new dispensation come to power in 1994, the first of the new studies namely, Third International Mathematics and Science Study (TIMSS) was implemented in 1994/1995. This was followed by its repeat study of Grade 8 pupils in 1998/1999. These studies were well-timed and well-placed to provide baseline data to the new democracy and its policymakers, curriculum developers and education officials at all levels.

As more than $80 \%$ of the South African TIMSS 1999 sample comprised schools, which are disadvantaged to some extent in terms of human and physical resources, it was critical that an analysis of the data from the science teachers' questionnaire was done to ascertain the effect of the conditions within these disadvantaged schools' science classrooms on the students' science performance as compared to those pupils in classes deemed more 'advantaged'.

More specifically, the research questions that are addressed in this article are (1) To what extent do the classroom conditions, teachers' characteristics and school resources differ across schools in South Africa? (2) What is the relationship between classroom conditions, teachers' characteristics and classroom resources and science achievement and how do these differ across schools?

A brief overview of relevant literature on factors influencing science performance is given in the next section, followed by sections on background information on the SA TIMSS 1999 study and conceptual framework for this research. Then the research and analysis methods are described and the research findings presented and discussed.

Classroom-level factors associated with performance in science factors affecting performance include time on tasks, homework, teacher knowledge, textbook provision, libraries, teachers' experience and class size. In addition, laboratories are seen as important for effective schooling (Howie, 2005). Taylor, Pressley, and Pearson (2000) argue that the factors that result in effective schools consist of two components namely instructional factors on a classroom-level and organisational factors on a school-level, both of which are equally important.

Furthermore, effective teachers are characterised by excellent classroom management skills, providing balanced instruction and students who are often

\footnotetext{
${ }^{2}$ An outcomes-based curriculum introduced post-1994 and intended for full implementation which was fraught with difficulties and had to be overhauled.
} 
working in small groups. Teaching style is also of importance, specifically handson activities, as well as, technology and integrated learning experiences where the foci are on reasoning and problem-solving abilities (Adam, Brower, Hill, \& Marshall, 2000). Also Shavelson and Baxter (1991) believe that hands-on science is of importance and teacher planning should be an integral aspect of instruction. Presentation of content-based lessons, based on well-designed lesson plans with adequate notes and textbooks are of important as well as the use of additional resources along with the textbooks (Rogan \& Grayson, 2003). Homework, belief in the efficacy of science, class size, orderly classroom environment, teacher experience and a readiness to teach a range of science topics were also found to be of importance when analysing the TIMSS 1999 data across countries (Martin, Mullis, Gregory, Hoyle, \& Shen, 2000).

Finally, Bos (2000) lists possible classroom-level factors that make a difference as being gender, experience, instructional time, class size, teacher beliefs, curriculum content coverage, cooperative learning, homework and resources.

\section{TIMSS-1999 in South Africa}

TIMSS 1999, also known as TIMSS-Repeat or TIMSS-R, was a replication study. It followed 4 years after the first TIMSS study in 1995 (for more details on SA participation and the results see Howie, 2001, 2002). This study was designed to provide trends in 8th grade mathematics and science achievement with reference to an international context (Martin, Mullis, Gonzalez, et al., 2000). The South African sample, which was nationally representative and stratified by province, initially included 225 schools to accommodate inter-provincial analysis. However, 194 schools, 190 science teachers and 8147 pupils were ultimately included in the dataset (Howie, 2005).

Achievement data were collected through mathematics and science tests and performance assessment tests. In addition questionnaires were administered at the national and schoollevel. At school level, based on a review of the school, teacher and student factors shown in previous research to be related to student achievement, questionnaires were developed for the school principal, the mathematics teacher, the science teacher and the student.

\section{Conceptual framework}

The conceptual framework for this research is the same as for the larger project, namely TIMSS 1999. Nonetheless, it is highly relevant for the discussion of classroom-level factors that the audience is introduced to the conceptual framework underpinning the research project.

The model shown in Fig. A1 [at end of article] presents the education system in terms of inputs, processes and outputs. A detailed discussion of the framework can be found in Howie (2002) and the reader is encouraged to refer to this 
source for further details. For the purpose of this article, teacher characteristics and school quality under antecedents, curriculum quality, teaching conditions and instructional quality under practice are the components of investigation for this research. The variables contained within each of these components are detailed later in the paper.

\section{Research and analysis methods}

As stated earlier, the research questions guiding this paper refer to how the classroom conditions, teachers' characteristics and school resources differ across schools in South Africa and how these variables relate to science achievement across schools.

The variables were identified from the teacher questionnaire with a few schoollevel variables (identified from the school questionnaire) such as enrolment for the school, per grade and average class size; limitations to education due to shortages of general resources and of science specific resources; and the location of the school.

\section{Identification of advantaged and disadvantaged groups}

The school-level variableswere used to evaluate the school and classroom data and to classify schools as being more or less advantaged. The measure of shortages of general resources (scale of $0-15$ ) was computed after schools had indicated that there were no shortages, a little shortage, some shortages or a lot of shortages. These general resources included heating and lighting, instructional space, budget for supplies, school buildings and instructional materials. A high score indicated a lack of general resources. Likewise similar measure (scale of $0-18$ ) was calculated for the science specific resources. A high score on this measure indicated a lack of science specific resources. Principals indicated whether or not there were shortages of laboratory equipment, computer software, computer hardware, calculators, audio-visuals and library materials.

On the basis of these measures, a further scale was developed combining scores from both measures, the measure of being disadvantaged on both a school-level (using the general resources) and on class-level (using the sciencerelated variables). The data was analysed in four groups where teachers teaching in classes with a low score on science resources indicated that there were few shortages with resources and therefore that teacher and classroom were considered more advantaged. The inverse was true in calculating the extent of disadvantaged indicated by a high score on either scale for general or for science resources. These four groups were identified as most advantaged, advantaged, disadvantaged and most disadvantaged. The original scales for both factors were a four-point scale (none, a little, some, a lot (of shortages). For general resources, the following scores were recoded: $0-5$ was most advantaged; 6-10 advantaged; $10.5-12$ disadvantaged; and 12.5-15 most 
disadvantaged. For the science resources, the following were recoded based on the distributions of the data: 0-5 most advantaged; 6-10 advantaged; 11-17 disadvantaged; and 18 was most disadvantaged. Thereafter the two scales were combined into an index for disadvantage. From the combined scores or sumscore, the scores were re-categorized into four points (scores 2 and 3 became 1, 4 and 5 became 2, 6 and 7 became 3 and 8 became 4) with 1 being advantaged and 4 being most disadvantaged.

The data explorations for research question 2 aimed at identifying factors that influence achievement in science in South Africa overall (and for each of the four groups mentioned above) required scale and path analysis. The first step in the analysis plan was to produce univariates of the possible classroom-level factors were analysed. Then Principal components analysis and reliability analysis were carried out on sets of items referring to one factor (see Appendix C). Factors with a reliability coefficient Cronbach a of at least .50 were selected as composite variables (Howie, 2002).

Correlations were undertaken between these factors and achievement (as the dependent variable) and factors with a correlation higher than .22 (see Howie, 2002) were included for further scrutiny and discussion in this paper. These correlations were conducted firstly for the whole sample of 185 teachers and thereafter for each of the four groups individually to better understand the dynamics and explanatory factors for each group.

Comparisons were made between four groups of teachers (most advantaged, advantaged, disadvantaged and most disadvantaged) based on teacher characteristics, classroom conditions and school resources. To test to what extent differences existed within these components for these four groups, an analysis of variance and chisquare tests were applied where appropriate. In this paper only significant differences $(a=.05)$ are specifically mentioned. Where no difference was found, no result is given. Thereafter the testing between the four groups, more in-depth analyses were undertaken within each group.

\section{Research findings}

The findings related to the first research question on the extent of the variation in school resources, classroom conditions and teachers' characteristics are described across South African schools. The findings are presented using the components extracted from the conceptual framework. These are first presented in relation to an analysis of the science achievement for each of the four groups of teachers (most advantaged, advantaged, disadvantaged and most disadvantaged). Then the findings are given for the variations in antecedents, namely school quality and teachers characteristics. This is followed by the practice components, namely teaching conditions, curriculum quality and instructional quality. Thereafter the relational analyses are undertaken 
in order to ascertain the extent of the variation in science achievement attributable to these antecedents and practice constructs.

\section{Variation in classroom conditions, teachers' characteristics and resources across South African schools}

Firstly schools are identified in terms of the level of disadvantage using variables from the construct school quality. Variables under this construct were used to divide the sample of teachers into those teaching at more advantaged schools as opposed to those with more disadvantaged characteristics. In the findings [see Table 2 at end of article], the analysis is presented in terms of these four groups and a description of the total sample is also given.

Thereafter, the science achievement is analysed and discussed and this is followed by a discussion of the constructs, namely teachers' characteristics, curriculum quality, teaching conditions, and instructional quality which are analysed in terms of the whole group of teachers and then a comparison is made of these constructs by the four categories of relative advantage (as described in the Research design section) in the sections to follow.

The factors below do not reflect all of those emanating from school quality as for the purpose of this paper, the variables believed to expose conditions reflecting greater or lesser advantage were selected. Therefore, school quality factors related to location of the school and the size of the school, Grade 8 and average class size, the general resources of the school and the science class resources are reported. The general resources and science resources were combined into an index (a detailed description of the construction of the index may be found in the Research design section). The means for each category in the disadvantaged index are presented in Table 2.

In total $17 \%$ of the schools and the tested science classroom were considered most advantaged, $29 \%$ were deemed advantaged, 37\% disadvantaged and $17 \%$ most disadvantaged in terms of the lack of resources at both levels. The findings related to school quality are presented, in these four groups together with the total [in Table 2].

The principals were asked to categorize the locale within which the school was situated into either an isolated rural area, village within a rural area, on the outskirts of a town or city or close to the centre of town or city (Table 3 [ at end of article]). During the time of Apartheid, socalled "non-Europeans" were moved to townships which were built outside the main centres. This isolated the African, Colored and Indian people and kept them away from amenities available to Whites. This form of disadvantage can be seen in the data (Table 3) where the most severely disadvantaged and disadvantaged schools and classrooms are found in isolated rural areas and other rural settings. Only a tiny proportion of the schools were found to be situated in an isolated area. 
A comparison of school quality factors was undertaken related to the enrolment of pupils at the school, the number of pupils in Grade 8 and the average class size in Grade 8. This revealed (Table 4 [at end of article]) that the most advantaged classes were in schools with larger enrolments at school and in Grade 8 . The average Grade 8 class was also smaller but nonetheless was beyond the national policy of 40 in a class. However, the most disadvantaged classes had smaller enrolments in the grade than the more advantaged classes, but had larger average class sizes.

A number of factors were tested for differences across the four groups amongst the analyses in this section, however, most were found not to be significant. Unless otherwise stated, no differences are significant $(a=.05)$.

\section{Science achievement}

Internationally South African pupils attained very low scores compared to their peers and were ranked 38 out of 38 countries participating (Howie, 2001; Martin, Mullis, Gonzalez, et al., 2000; Martin, Mullis, Gregory, et al., 2000). In Table 5 [at end of article] the class mean scores calculated for each of the teachers' classes show a linear relationship with the decreasing degrees of advantage. The group of most advantaged teachers' classes attained the highest scores and over than 120 points more (international mean is 500 points, standard deviation (S.D.) is 100 points) and the group of most disadvantaged teachers' classes. An analysis of variance revealed that a difference existed between the four groups $(\mathrm{F}=.026$, Sig. $=.000)$, indicating that pupils from the most advantaged and advantaged schools achieved (Table 5) significantly higher scores than pupils in the disadvantaged schools.

A significant difference was found in scores of pupils in more or less advantaged settings when taught by teachers of different racial profiles $(F=80.381$, Sig. $=.000)$. However, within the advantaged settings pupils in classes taught by White and Colored teachers achieved higher scores (Table 6 [at end of article]). Pupils in classes taught by African teachers consistently achieved the lowest scores. The mean scores of children taught by Asian, Colored and Indian teachers were higher than those taught by African teachers, but lower than those taught by White teachers (with the exception of those in the most advantaged classrooms).

Pupils of teachers in more advantaged settings consistently achieved higher scores across all race groups (see Table 6). As mentioned earlier, the majority of teachers in all four groups were African.

A significant difference was found between the scores of pupils from urban schools (inner city and outskirts of city) and those from rural schools 
$(F=11.606$, Sig. $=.000)$. This meant that on average children from urban schools attained the highest mean scores for science (Table 7, last column [at end of article]).

When analysing this phenomenon further, a significant difference was also found for location across the four groups related to disadvantage $(F=8.026$, Sig. $=.000)$. The lowest scores (mean score of 147$)$ found were those of the pupils whose teachers taught in the most disadvantaged settings, namely in the isolated rural areas. The pupils of the teachers in the most advantaged schools consistently achieved higher mean scores than those from disadvantaged schools. Interestingly, in the inner city pupils from the most disadvantaged schools achieved higher scores than their peers in the disadvantaged schools.

\section{Teacher characteristics}

The data was obtained from 185 science teachers out of the 190 teachers that participated. The average age of science teachers was found to be between 28 and 30 years. Teachers in the most advantaged settings appeared to be the oldest out of the four groups and those in the advantaged group were the youngest.

Fifty-five percent of the pupils sampled were taught by female teachers. Both the most advantaged $(62.5 \%)$ and the most disadvantaged groups (64\%) contained the largest percentage of teachers who were female. However, pupils in a disadvantaged setting were more likely to be taught by a male teacher $(55 \%)$.

In total of the 185 teachers, $74 \%$ were African, reflecting the country's demographics (Table 8 [at end of article]). A very low percentage of Asian and Indian teachers were found in this sample (.5 and $1 \%$, respectively) and none were situated in advantaged settings. Three percent of the most disadvantaged classes were taught by an Indian teacher. Within all four groups, most of the teachers were African in each group although there was a significant difference in the racial profile of teachers in each category $(F=2.731$, Sig. $=.045)$. The highest percentage of African teachers was found in the most disadvantaged group where they comprised $90 \%$.

The largest percentage of White teachers was found in the most advantaged setting (22\% of the teachers in this category were White) and only $4 \%$ of the disadvantaged classes were headed by a White teacher. No White teachers were found in the most disadvantaged classes. Twenty-eight percent of the advantaged classrooms were staffed by Colored teachers who also comprised $17 \%$ of the disadvantaged classrooms.

A far greater proportion of teachers in more advantaged classrooms spoke the medium of instruction (either English or Afrikaans at that time) as their home 
language compared to those in less advantaged settings. A very small proportion of teachers spoke the same language as the medium of instruction in the most disadvantaged classrooms.

On average, teachers had taught science for 9 years. Of the teachers who responded $45 \%$ of the South African pupils are taught by teachers with nonscience majors (i.e. other than biology, physics and chemistry) (Martin, Mullis, Gonzalez, et al., 2000; Martin, Mullis, Gregory, et al., 2000). Biology was the most common specialisation (52\%) for teachers majoring in science (Table 9 [at end of article]). This was also the case across all the four groups, although amongst teachers in the most advantaged classes, an equal number had taken physics (16:16) which was also the case with the disadvantaged group (36:35). In most groups, science education appeared to be the least common specialisation except for the teachers in the advantaged category. Note that teachers would typically qualify with two specialisations and therefore the numbers do not add up to the numbers of the respective groups.

On average teachers reported having had 2.9 years of teacher education (see Table 10 [at end of article]). Most of the teachers (77\%) had obtained either College of Education diploma or a Bachelors degree from university or the former technikons. More than one-fifth of the teachers (22\%) had only completed secondary school and had no further qualifications. Only one teacher had a postgraduate degree (either a masters' degree or a doctoral degree). Eighty-nine percent reported that they had a training certificate.

A closer look within the groups (see Table 10), teachers from the most advantaged classes had the most teaching experience, although those from disadvantaged settings also had more than 9 years experience. The teachers from the most advantaged schools also had on average a higher level of education ( $81 \%$ had bachelors or equivalent and these schools had the only teachers with postgraduate qualifications) and years of teacher training compared to all other groups. All of the teachers from all groups had completed secondary school, but a higher number of teachers from disadvantaged (including most disadvantaged) schools had only secondary school qualifications.

The most disadvantaged group did not have the least of all the factors listed in the table, but tended to be lower in percentage than the most advantaged group on all factors.

\section{Curriculum quality}

For this paper, the factors on curriculum quality are limited to "obstacles inhibiting the teacher's ability to teach", which was shown to be a key factor in mathematics achievement (Howie, 2002). 
Teachers were asked about the obstacles that they faced that limited their teaching practices (Table 11 [at end of article]). These items were grouped into two indices, obstacles relating to the students (ranging from 7 to 28) and the other relating to the teaching and class level factors (range of 8-28). The student factors included: students with different academic abilities, students with a wide range of backgrounds, students with special needs, uninterested students, disruptive students, low morale amongst students and threats to students' safety. The teaching factors included shortages of computer hardware, computer software, instructional equipment, inadequate facilities, a high student: teacher ratio and a low morale amongst the teaching staff.

Across three of the groups, teachers rated fewer obstacles related to pupils, as limitations to their teaching practice than those related to the teaching and class. Interestingly the most disadvantaged classrooms listed their biggest obstacles as pupil related and far fewer teaching related.

Teachers in the most advantaged schools reported the lowest pupil-related obstacles but relatively higher teaching-related obstacles. The former in this case is more obvious as these are most likely high fee-paying environments that attract a different kind of pupil. However, the latter is more surprising and less obvious to explain. When tested, differences were revealed between the groups for the obstacles that were teacher related $(F=3.447$, Sig. $=.018)$ but not for the student-related obstacles. Teaching-related obstacles appeared similar in advantaged schools compared to disadvantaged schools.

\section{Teaching conditions}

In this section, class size, teaching load of the science teachers and dedication and perceptions of the science teachers is included.

The average class size which was tested ${ }^{3}$ was 52 pupils $(n=185)$ which is one of the largest class sizes on average in TIMSS'99 for science classes. This is also higher than the number of pupils calculated in the international report, but is a result of reducing the dataset and working with only complete data (i.e. incomplete records with large amounts of missing data were removed from the analysis). Across the four groups there was a wide disparity with the most advantaged classes containing the smallest classes which were still above government's policy of 40 pupils per class at 44.5 pupils. The largest class size was for the disadvantaged teachers at 54 pupils (Table 12 [at end of article]).

The teaching load was analysed in terms of the teaching time spent and the activities related to work (Table 13 [at end of article]).

Teachers reported on the amount of time that they spent on lesson planning outside school hours, the percentage of time spent on teaching activities and the 
perception they had of society's and the pupils appreciation for the work they do (Table 14 [at end of article]).

\section{Instructional quality}

In this paper instructional quality comprises the proportion of first language pupils in the science class, the teaching style of science teachers and teachers' beliefs.

Language as mentioned earlier in the paper is a major cause for concern in South African schools. It is also often implicated as being the cause for pupils failure as more than $80 \%$ of the children learn in a second language. Taking this into account, a national option in the South African TIMSS study was introduced to investigate the relationship of language and performance in mathematics and science. The hypothesis was that children learning in their first language were more likely to attain higher marks for science than children who did not.

\footnotetext{
${ }^{3}$ As opposed to the average class size in general reported by the principal for Grade 8 (Table 4).
}

As expected, the highest proportion of first language pupils (.44) were found in the most advantaged classes with the lowest proportion being found in the most disadvantaged group (.19). As part of the outcomes-based education (OBE) curriculum, group work has had increasing emphasis. Table 15 [at end of article] presents the responses of teachers who were asked about the frequency with which they placed the children in pairs or groups for their learning activities.

Teachers were asked to what extent they agreed with a number of statements about the nature of science and science teaching (see Table 15). These included: (1) science is primarily a formal way of representing the real world; (2) science is primarily a practical and structured guide for addressing real situations; (3) some students have a natural talent for science and others do not; and (4) is important for teachers to give students prescriptive and sequential directions for doing science experiments.

With the majority of the teachers in South Africa strongly agreeing or agreeing to the four statements, it was important to review these across the four specified groups. Perhaps not so surprising was that the teachers from the most advantaged schools had the lowest score on the index suggesting an independence in thinking from other teachers.

Teachers were also asked about their beliefs to what extent particular abilities were important for students' success in science, namely (1) to think in a sequential and procedural manner; (2) to be able to think creatively; (3) to 
understand how science is used in the real world; (4) to be able to provide reasons to support their conclusions.

\section{The relationship between classroom conditions, teachers' characteristics and resources with science achievement and variations across schools}

In order to address the second research question, factor analyses, reliability analyses and correlations (Pearson Product Moment) were applied to the variables comprising the indices and scales reported in the previous section with the science achievement (mean score) as the dependent variable (in the correlations). The details of the reliability analyses are contained within the appendices and the results of the correlation analyses are reported below.

In order to undertake the exploration, certain preparatory steps were undertaken and a number of the classroom factors included composites which were developed through a process of factor and reliability analyses. The reliability analyses indicated that the majority of composite scales could be used for further analysis with the exception of class activities. The other composite scales obtained alphas of above .50 with the percent of time spent on teaching activities and obstacles to teachers' ability to teach in terms of teaching-related factors obtaining the highest alphas for both mathematics (.84 and .86) and science (.84 and .81). After a reliability analysis was undertaken a correlation matrix was analysed in relation to the aggregated science score and between variables. An exploration of all the items within each factor was undertaken in the correlations and some interesting patterns emerged from the data.

Few of the factors correlated very strongly across all of the groups and for the overall sample of teachers. Table 16 [at end of article] indicates a summary of the results in the form of a positive of negative correlation ( \pm ) or no correlation (0) (whilst the actual coefficients can be found in Appendix E). The strongest correlations were found for the teachers' home language, the proportion of first language speakers in the class, the race of the teacher, location of the school and the extent to which teachers felt appreciated (where overall and three out of the four groups, a relationship was found with science achievement). In all cases a positive relationship was found which indicated that in classes where the teachers' home language was the same as the medium of instruction, where there was a higher proportion of first language speakers amongst the pupils, where there was a either a Colored, Indian or White teacher, where the school was situated in an urban area and where the teacher felt appreciated by the society and his/her pupils, the science achievement scores tended to be higher than in classes where this was not the case.

With regard to the teaching conditions, teacher characteristics and resources, these are discussed separately below. 


\section{Teacher characteristics}

A number of teacher characteristics were included in the analysis: age, gender, race, language, highest qualification, field of specialisation, and years of experience. Of these characteristics only two factors, highest qualification and teachers' home language, in the overall sample met the criterion of .22 for inclusion (see Howie, 2002). A positive relationship was found between higher qualifications and the teachers' home language with science achievement (Table 16). However, within groups there were a number of correlations found with science achievement. In the most advantaged group, positive correlations were found for age, highest qualification, number of years of experience, home language and the specialisation field of science education whilst negative correlations were found for the gender of the teacher. There was only one correlation found for the disadvantaged group and that was home language. However, in the most disadvantaged classes correlations were found with age, home language, highest qualification and specialisations in biology and physics. Pupils in these classes tended to perform better in science where there were younger teachers with better qualifications, where teachers' home language was the same as the medium of instruction and specialisations in biology and physics.

\section{Teaching conditions and resources}

The following factors were included for analysis with regard to teaching conditions: teachers' beliefs, teaching style, attitudes to teaching, teacher load, proportion of pupils speaking the medium of instruction at home (i.e. their first language), location of the school and class size (the size of the class tested). Of all the factors included, only two factors in the overall sample was found to be related to science achievement. These were the total teaching time and the proportion of the pupils in the class who spoke the medium of instruction as their first language at home.

The relationships were also examined within each group. Within the most advantaged group, correlations (most of which were significant) were found for all the factors.

Fewer relationships were found with regard to the disadvantaged schools. Correlations were found with teachers' load, attitudes to teaching, and location. This meant that children in disadvantaged classrooms tended to achieve better mean scores for science where teachers spent more time teaching science and at work in general, where teachers felt appreciated and where their schools were based in urban areas.

\section{Resources}

As mentioned earlier, a number of resource variables on school level were combined in order to categorize the schools into four categories of relative advantage/disadvantage. The resources referred to here are as reported on 
classroom level by the science teacher. Correlations were found in the most advantaged group with teaching-related obstacles viewed by the teacher as limiting their ability to teach science effectively but not within the other three groups. No other group was found with a correlation on this factor.

\section{Conclusions and discussion}

This article sought to ascertain the extent of the gap existing between classes of different schools regarding classroom conditions, teacher characteristics and teacher actions in South Africa and secondly to determine the extent to which a variation in conditions and teacher actions affects the achievement in science in SA classrooms. This was partly inspired by the shocking revelation by Hofmeyer and Buckland, back in 1992 (predemocracy) of the vast disparities in the education system across race groups. They reported high pupil: teacher ratios, a significantly higher percentage of under-qualified teachers, a gross under-expenditure on African children, all of which plausibly explained the far lower pass rate of the Grade 12 African pupils at that time.

The data for this article was collected 6 years after that significant work and therefore the extent to which the system had addressed some of those issues seemed pertinent. Further inspiration was drawn from the previous work on the mathematics achievement data (Howie, 2002) which had made some startling revelations about the relationship of language and achievement in mathematics. This article drew on that work and its conceptual framework and the literature on influences on science achievement at the classroom level.

Within the conceptual framework, the components of interest were the antecedents, namely school quality and teachers' characteristics and the practice components, namely teaching conditions, curriculum quality and instructional quality. In order to study the variation of the factors and their relationship to achievement, four groups of schools were constructed depicting relative levels of advantage and disadvantage. In total $17 \%$ of the schools and the tested science classrooms were identified as being most advantaged, $29 \%$ were deemed advantaged, $37 \%$ disadvantaged and $17 \%$ most disadvantaged in terms of the lack of resources at both levels.

The relationships of the factors mentioned above to the mean science score of the class were analysed by correlations and the differences tested by ANOVAs. In general, few factors were strongly correlated overall (.70 and higher) and across all of the groups The strongest correlations found were teachers' home language (if it was the same as the medium of instruction), the proportion of first language speakers in the class, the race of the teacher, location of the school and the extent to which teachers felt appreciated. In all cases, a positive relationship with achievement in science was found where in classes where the teacher's home language was either English or Afrikaans (i.e. the same as the language of instruction), where there was a higher proportion of first language 
speakers amongst the pupils (i.e. English speaking or Afrikaansspeaking), where there was either an Asian, Colored, Indian or White teacher, where the school was situated in a urban area and where the teacher felt appreciated by the society and his/her pupils. Where this occurred, the science achievement scores tended to be higher than in classes where this was not the case. Furthermore, learners taught by teachers from the most advantaged classes attained the highest scores and over 120 points more than the most disadvantaged groups' classes. Pupils from the most advantaged and advantaged schools achieved higher scores than pupils in the disadvantaged schools.

The teachers' racial profile related to performance may be an important variable to monitor from the perspective of ensuring change in education. Inequalities remain firmly entrenched in the system and a high correlation with achievement is one indicator of the large variation still visible in education. Seventy-four percent (a close reflection of the demographic profile of the country) of the pupils were taught by an African teacher. The remaining 36\% of pupils were taught by Asian, Colored, Indian or White teachers. A disproportionate number of African teachers teach in the most disadvantaged schools (90\% of teachers) and the inverse is true of White teachers teaching in the most advantaged schools $(22 \%)$ where the pupils they teach comprise only $7 \%$ of the total sample. The largest number of Colored teachers was found in advantaged schools, and they comprise $17 \%$ of the total sample. The findings emerging from this research seem to confirm that within classrooms the disparities still run along racial lines as reported in 1992.What is interesting is not that pupils in classes taught by African teachers consistently achieved the lowest scores, but that pupils of African teachers in more advantaged schools achieved higher scores than those in disadvantaged schools. As with the variation of funding of pupils at school according to race, there was likewise a sliding scale of provisioning of teacher education in terms of race. African teachers were offered 2- or 3-year certificate or diploma of education in largely poorly resourced Colleges of Education. Colored and Indian teacher trainees could enroll for 3- or 4-year qualifications in slightly better provisioned Colleges of Education and even university degrees at inadequately resourced universities. At the top end of this scale, White teacher trainees were trained at either very well resourced Colleges of Education for 4 years or universities where they studied education usually as a postgraduate qualification.

This sliding scale is evident in the data in Table 6. However, the data also suggest that the vicious cycle can be broken if conditions within schools can be improved and teachers are better prepared. Whilst this would at first glance both reasonable and logical, 15 years after democracy, many schools do not have toilets, electricity, running water and insufficient classrooms. These data suggests that the science achievement is unlikely to improve greatly until certain minimum conditions are in place. These data also reveal that pupils of teachers 
in more advantaged settings consistently achieved higher scores across all race groups.

The home language of the teacher and the race of the teacher are intertwined. Very few African teachers from 1999 would speak English or Afrikaans at home as their first language. Amongst the younger generation, there is an increasing tendency now to do this, but it would be rare for the older generation. Colored teachers and White teachers would almost certainly speak English or Afrikaans at home, whilst Indian teachers would certainly be fluent in English and for many African teachers it would not be their first language. This means that it would be most likely that the African teachers would be the group teaching in a second or third language. However, as many are not fluent in either English or Afrikaans, this leads to a common practice of code-switching where the speaker reverts from the medium of instruction to their (and/or their pupils') first language during class. This can also reduce the exposure of the official medium of instruction to the pupils to the point they never become proficient in the medium of instruction and hence may perform poorly in assessments in that language. It should also be said that few Colored, Indian and White teaches are fluent enough in an African language to teach in that language and therefore this is also a severe restriction that limits the deployment of teachers greatly.

In conclusion of the teacher characteristics, teachers in the disadvantaged group were examined more closely. The data suggest that pupils in classes that performed better were those that had younger teachers, who had better qualifications and a specialisation with either biology or physics and whose teachers' home language was the same as the medium of instruction.

Two factors amongst the many included under the Practice variables (curriculum quality and instructional quality), namely the teaching conditions and resources, were found to correlate with science achievement overall. These were the total teaching time (a factor under curriculum quality) for science and the proportion of the pupils in the class who spoke the medium of instruction as a first language. The total teaching time may be regarded as the opportunity to learn which is well known as a key factor in predicting achievement. Attendance by teachers and pupils in some schools may be problematic and absentee rates can be high. This factor is one of the most important policy related factors that can be addressed (unlike most the previous teacher characteristics). It appears fairly obvious that if children are given more opportunity to learn and teachers spend more time in teaching the subject that it is more likely that learning takes place and that achievement scores could improve. Importantly, teaching time was found to correlate with achievement in most disadvantaged schools implying that pupils of teachers in disadvantaged schools achieved higher scores in science when their teachers spent more time teaching science, which was also the case for the most advantaged schools. 
The second factor that correlated with science achievement was pupils in the class who spoke the medium of instruction as a first language which is related to Instructional Quality from the conceptual framework. As with the home language of the teacher, the language of the pupil is also intertwined with race and socioeconomic factors. Language is a major concern in South Africa, a multilingual country of 11 official languages but where in policy children have the right to be educated in their first language, this seldom happens. Most secondary schools have the policy of implementing either English or Afrikaans as the medium of instruction and more than $70 \%$ of the pupils in South Africa learn in a second, third or even foreign language.

Whilst there was a strong correlation within the most advantaged group implying that first language speakers tended to achieve better science scores, there was no correlation in the most disadvantaged schools. One explanation was the lack of variation as these schools would more likely be dominated by African learners and almost all of whom would be second language speakers.

A couple of relationships were found for two of the resource factors, namely obstacles to the teachers' ability to teach which were teaching-related, as opposed to pupil related, and computers outside of the classroom. Regarding the former, teaching-related obstacles included the lack of computer hardware and software, facilities and resources. These were previously distributed on a sliding scale as mentioned earlier and therefore are often also racially related. However, whilst this factor correlated within the overall sample, a relationship was only found in the most advantaged group of schools. Pupils in schools where the teachers did not have a lack of resources or experience this shortage as a problem, tended to achieve higher scores. The relationship with computers outside the classroom was also found only with the most advantaged group. This may also be a general indicator for wealthier schools rather than the presence of the computers themselves. It is very unlikely that many of the schools in either disadvantaged group would have these computers as only approximately $13 \%$ of the schools in SA have computers in their schools and most often this has happened in privileged schools or as a result of donations to underprivileged schools.

\section{Final word}

Vast inequalities still exist within the education system and these data confirm this. Clearly there is large variation in conditions, teacher characteristics and resources across South African schools. However, there were variables where the most disadvantaged schools did not vary significantly from other groups of schools. Nonetheless, one cannot look at individual factors in isolation as illustrated in this article, as so many factors are interlinked. What is clearly needed though is a coherent strategy able to address the "old inequalities" and 
one that clearly defines the minimum conditions required for effective teaching and learning to take place. This strategy has to be implemented as a matter of urgency to ensure that these conditions are in place for all schools in South Africa.

This research started as an investigation into science achievement and the correlates thereof in the South African context. A future study needs to investigate the interdependence of these and other variables. Furthermore as these are 1999 data, further research needs to investigate the data emerging from the later studies to evaluate the progress in closing the achievement gap. This gap needs constant monitoring in order to ensure that it does not widen but rather narrows appropriately, i.e. weaker schools improve achievement and stronger schools do not decline. In order to do this, relevant data has to continue to be collected in a valid and reliable way so that researchers and policymakers gain insights into what is working effectively or otherwise.

\section{References}

Adam, K., Brower, S., Hill, D., \& Marshall, I. (2000). The components of an effective mathematics and science middle school: Standards, teaching practices and professional development. Research Report retrieved from the ERIC database.

Bos, K. (2000). Exploring influencing factors on achievement in mathematics in Grade 8 in Western European Countries. Contribution CURRIOZA, April 4, 2000.

Hofmeyer, J., \& Buckland, P. (1992). Education system change in South Africa. In R. McGregor \& A. McGregor (Eds.), McGregor's alternatives. Kenwyn: Juta's \& Co.

Howie, S. J. (2001). Mathematics and science performance in Grade 8 in South Africa 1998/1999. Pretoria: Human Science Research Council.

Howie, S. J. (2002). English language proficiency and contextual factors influencing Mathematics achievement of secondary school pupils in South Africa. Published PhD thesis, University of Twente.

Howie, S. J. (2005). Conceptual factors at the school and classroom level related to pupils' performance in mathematics in South Africa. Educational Research and Evaluation, 11(2), 123-140.

Martin, M. O., Mullis, I. V. S., Gonzalez, E. J., Gregory, K. D., Smith, T. A., Chrostowski, S. J., et al. (2000a). TIMSS 1999: International science report. Boston: International Study Center. 
Martin, M. O., Mullis, I. V., Gregory, K. D., Hoyle, C., \& Shen, C. (2000b). Effective schools in science and mathematics. Chestnut Hill: Boston College.

Rogan, J. M., \& Grayson, D. J. (2003). Towards a theory of curriculum implementation with particular reference to science education in developing countries. International Journal of Science Education, 25(10), 1171-1204.

Shavelson, R. J., \& Baxter, G. P. (1991). Performance assessment in science. Applied Measurement in Education, 4(4), 347-362.

Shavelson, R. J., McDonnell, L. M., \& Oakes, J. (1987). Indicators for monitoring mathematics and science education: a sourcebook. Santa Monica: Rand Publications Corporation.

Taylor, B. M., Pressley, M., \& Pearson, D. (2000). Effective teachers and schools: Trends across recent studies. Retrieved 15 June, 2005, from http://education.umn.edu/ci/taylor/taylor1.html

\begin{tabular}{lllll}
$\begin{array}{l}\text { Table 1 } \\
\text { Comparative education statistics } 1989\end{array}$ & & & \\
\hline & White & Indian & Colored & African \\
\hline Pupil:teacher ratios & $17: 1$ & $20: 1$ & $23: 1$ & $38: 1$ \\
Under-qualified teachers & $0 \%$ & $2 \%$ & $45 \%$ & $52 \%$ \\
$\begin{array}{l}\text { Per capita expenditure } \\
\text { including capital }\end{array}$ & $\mathrm{R} 3082.00$ & $\mathrm{R} 2227.01$ & $\mathrm{R} 1359.78$ & $\mathrm{R} 764.73$ \\
Std 10 (Grade 12) pass rate & $96 \%$ & $93.6 \%$ & $72.7 \%$ & $40.7 \%$ \\
\hline Hofmeyer and Buckland (1992 & p. 22). & & &
\end{tabular}

Table 2

Shortages of general and science resources at teachers' schools

\begin{tabular}{|c|c|c|c|c|c|c|c|c|c|c|}
\hline \multirow[t]{2}{*}{ Shortages of } & \multicolumn{2}{|c|}{$\begin{array}{l}\text { Most advantaged } \\
(N=32(17 \%))\end{array}$} & \multicolumn{2}{|c|}{$\begin{array}{l}\text { Advantaged } \\
(N=53(29 \%))\end{array}$} & \multicolumn{2}{|c|}{$\begin{array}{l}\text { Disadvantaged } \\
(N=69(37 \%))\end{array}$} & \multicolumn{2}{|c|}{$\begin{array}{l}\text { Most disadvantaged } \\
(N=31(17 \%))\end{array}$} & \multicolumn{2}{|c|}{ Total $(N=185)$} \\
\hline & Mean & S.D. & Mean & S.D. & Mean & S.D. & Mean & S.D. & Mean & S.D. \\
\hline General resources & 4.08 & 2.84 & 7.19 & 3.16 & 10.66 & 2.12 & 13.89 & .93 & 9.07 & 4.02 \\
\hline Science resources & 3.88 & 3.41 & 13.07 & 4.42 & 16.94 & 1.65 & 18.00 & 0 & 13.75 & 5.70 \\
\hline
\end{tabular}


Table 3

Percentage of pupils' teachers and the location of the school

\begin{tabular}{lcllll}
\hline & $N$ & \multicolumn{2}{l}{ Location } & \\
\cline { 2 - 6 } & & Isolated area & Village or rural ared & On outskirts of town/city & Inner city/town \\
\hline Most advantaged & 32 & 0 & 28 & 22 & 50 \\
Advantaged & 53 & 0 & 36 & 23 & 28 \\
Disadvantaged & 69 & 4.3 & 41 & 19 & 26 \\
Most disadvantaged & 31 & 6.5 & 48 & 37 & 17 \\
Total percentage of schools & 185 & 17 & 29 & 26 \\
\hline
\end{tabular}

Table 4

School quality factors related to the number of pupils in school, Grade 8 and the average class size for Grade 8

\begin{tabular}{|c|c|c|c|c|c|c|c|c|c|c|}
\hline \multirow[t]{2}{*}{ School quality factors } & \multicolumn{2}{|c|}{$\begin{array}{l}\text { Most advantaged } \\
(N=32)\end{array}$} & \multicolumn{2}{|c|}{$\begin{array}{l}\text { Advantaged } \\
(N=53)\end{array}$} & \multicolumn{2}{|c|}{$\begin{array}{l}\text { Disadvantaged } \\
(N=69)\end{array}$} & \multicolumn{2}{|c|}{$\begin{array}{l}\text { Most disadvantaged } \\
(N=31)\end{array}$} & \multicolumn{2}{|c|}{ Total $(N=185)$} \\
\hline & Mean & S.D. & Mean & S.D. & Mean & S.D. & Mean & S.D. & Mean & S.D. \\
\hline Grade size & 210 & 113.0 & 193 & 85.69 & 205 & 123.11 & 186 & 114.7 & 199 & 109.76 \\
\hline Class size & 41.6 & 11.87 & 46 & 11.40 & 47.5 & 12.99 & 46.5 & 14.49 & 45.9 & 12.70 \\
\hline
\end{tabular}

Table 5

Pupils' mean scores across all groups and in total

\begin{tabular}{|c|c|c|c|c|c|c|c|c|c|c|}
\hline & \multicolumn{2}{|c|}{$\begin{array}{l}\text { Most advantaged } \\
(N=32)\end{array}$} & \multicolumn{2}{|c|}{$\begin{array}{l}\text { Advantaged } \\
(N=53)\end{array}$} & \multicolumn{2}{|c|}{$\begin{array}{l}\text { Disadvantaged } \\
(N=69)\end{array}$} & \multicolumn{2}{|c|}{$\begin{array}{l}\text { Most disadvantaged } \\
(N=31)\end{array}$} & \multicolumn{2}{|c|}{ Total $(N=185)$} \\
\hline & Mean & S.D. & Mean & S.D. & Mean & S.D. & Mean & S.D. & Mean & S.D. \\
\hline Mean score & 331 & 141.19 & 261 & 99.04 & 245 & 95.44 & 210 & 73.71 & 258 & 108.46 \\
\hline
\end{tabular}

Note: Mean scores are rounded off. 
Table 6

Pupils science achievement by teacher's race group and level of advantage category

\begin{tabular}{|c|c|c|c|c|c|}
\hline \multirow[t]{2}{*}{ Racial grouping } & \multicolumn{4}{|l|}{ Level } & \multirow[t]{2}{*}{ Total } \\
\hline & Most advantaged & Advantaged & Disadvantaged & Most disadvantaged & \\
\hline \multicolumn{6}{|l|}{ African } \\
\hline$N$ & 23 & 34 & 52 & 28 & 137 \\
\hline Mean & 261 & 211 & 205 & 192 & 213 \\
\hline \multicolumn{6}{|l|}{ Asian } \\
\hline$N$ & - & - & 1 & - & 1 \\
\hline Mean & - & - & 404 & - & 403 \\
\hline \multicolumn{6}{|l|}{ Colored } \\
\hline$N$ & 2 & 15 & 12 & 2 & 31 \\
\hline Mean & 506 & 310 & 325 & 316 & 329 \\
\hline \multicolumn{6}{|l|}{ Indian } \\
\hline$N$ & - & - & 1 & 1 & 2 \\
\hline Mean & - & - & 458 & 476 & 467 \\
\hline \multicolumn{6}{|l|}{ White } \\
\hline$N$ & 7 & 4 & 3 & - & 14 \\
\hline Mean & 509 & 507 & 491 & - & 504 \\
\hline
\end{tabular}

No data in cells marked (-).

Table 7

Achievement in science by location of the school

\begin{tabular}{lcllll}
\hline & Most advantaged & Advantaged & Disadvantaged & Most disadvantaged & Total \\
\hline Isolated area & - & - & 226 & 147 & 184 \\
Rural village/town & 225 & 238 & 190 & 243 & 206 \\
Outskirts of town/city & 276 & 269 & 271 & 249 & 267 \\
Inner city & 414 & 282 & 200 & 209 & 321 \\
Overall mean & 331 & 261 & 245 & 258 \\
\hline
\end{tabular}

Table 8

Percentage of teachers per racial group per category of advantage

\begin{tabular}{llrrlc}
\hline & $\begin{array}{l}\text { Most } \\
\text { advantaged }\end{array}$ & Advantaged & Disadvantaged & $\begin{array}{l}\text { Most } \\
\text { disadvantaged }\end{array}$ & Total \\
\hline African & 72 & 64 & 75 & 90 & 74 \\
Asian & 0 & 0 & 1 & 0 & .5 \\
Colored & 6.5 & 28 & 17 & 6.5 & 17 \\
Indian & 0 & 0 & 1 & 3 & 1 \\
White & 22 & 7.5 & 4 & 0 & 7.4 \\
\hline
\end{tabular}


Table 9

Teachers' area of specialisation in science per category

\begin{tabular}{llllll}
\hline & Most advantaged $(N=32)$ & Advantaged $(N=53)$ & Disadvantaged $(N=69)$ & Most disadvantaged $(N=31)$ & Total $(\%)(N=185)$ \\
\hline Biology & 16 & 28 & 36 & 15 & 52 \\
Physics & 16 & 14 & 35 & 9 & 41 \\
Chemistry & 13 & 12 & 30 & 8 & 36 \\
Science Education & 11 & 14 & 24 & 7 & 29 \\
\hline
\end{tabular}

Table 10

Teachers' education, and teaching experience

\begin{tabular}{|c|c|c|c|c|c|c|c|c|c|c|}
\hline & \multicolumn{2}{|c|}{$\begin{array}{l}\text { Most advantaged } \\
(N=32)\end{array}$} & \multicolumn{2}{|c|}{$\begin{array}{l}\text { Advantaged } \\
(N=53)\end{array}$} & \multicolumn{2}{|c|}{$\begin{array}{l}\text { Disadvantaged } \\
(N=69)\end{array}$} & \multicolumn{2}{|c|}{$\begin{array}{l}\text { Most disadvantaged } \\
(N=31)\end{array}$} & \multicolumn{2}{|c|}{$\begin{array}{l}\text { Total } \\
(N=185)\end{array}$} \\
\hline & Mean & S.D. & Mean & S.D. & Mean & S.D. & Mean & S.D. & Mean & S.D. \\
\hline Years of teaching experience & 9.41 & 6.7 & 8.72 & 4.99 & 9.31 & 6.39 & 8.75 & 6.0 & 9.06 & 5.97 \\
\hline Highest level of Education & 2.86 & .42 & 2.78 & .40 & 2.73 & .44 & 2.75 & .42 & 2.77 & .42 \\
\hline Years of teacher training & 3.31 & 1.67 & 2.83 & 1.05 & 2.75 & 1.14 & 3.13 & 1.7 & 2.93 & 1.34 \\
\hline & \multicolumn{3}{|c|}{ Most advantaged } & Advantaged & \multicolumn{2}{|r|}{ Disadvantaged } & \multicolumn{3}{|c|}{ Most disadvantaged } & Total \\
\hline \multicolumn{11}{|c|}{$\%$ of teachers completing specific levels of education } \\
\hline Secondary only & \multirow{2}{*}{\multicolumn{2}{|c|}{$\begin{array}{l}16 \\
81\end{array}$}} & \multirow{2}{*}{\multicolumn{2}{|c|}{$\begin{array}{l}21 \\
79\end{array}$}} & \multicolumn{2}{|r|}{26} & \multicolumn{2}{|r|}{23} & & 22 \\
\hline $\mathrm{BA}$ or equivalent & & & & & \multirow{2}{*}{\multicolumn{2}{|c|}{$\begin{array}{r}14 \\
0\end{array}$}} & \multirow{2}{*}{\multicolumn{2}{|c|}{$\begin{array}{r}78 \\
0\end{array}$}} & & 77 \\
\hline $\mathrm{MA} / \mathrm{PhD}$ & \multicolumn{2}{|r|}{3} & \multicolumn{2}{|r|}{0} & & & & & & .5 \\
\hline$\%$ of teachers-teaching diploma & \multicolumn{2}{|r|}{91} & \multicolumn{2}{|r|}{87} & \multicolumn{2}{|r|}{91} & \multicolumn{2}{|r|}{87} & & 89 \\
\hline
\end{tabular}

Table 11

Obstacles to teaching

\begin{tabular}{|c|c|c|c|c|c|c|c|c|c|c|}
\hline & \multicolumn{2}{|c|}{ Most advantaged } & \multicolumn{2}{|c|}{ Advantaged } & \multicolumn{2}{|c|}{ Disadvantaged } & \multicolumn{2}{|c|}{$\begin{array}{l}\text { Most } \\
\text { disadvantaged }\end{array}$} & \multicolumn{2}{|l|}{ Total } \\
\hline & Mean & S.D. & Mean & S.D. & Mean & S.D. & Mean & S.D. & Mean & S.D. \\
\hline Obstacles pupil related & 16.91 & 3.65 & 17.85 & 4.2 & 17.36 & 4.31 & 21.66 & 4.53 & 17.42 & 4.20 \\
\hline Obstacles teacher related & 18.48 & 5.62 & 19.56 & 4.6 & 19.26 & 4.96 & 17.37 & 5.23 & 19.78 & 5.12 \\
\hline
\end{tabular}

Table 12

Average number of pupils in science classroom who were tested

\begin{tabular}{|c|c|c|c|c|c|c|c|c|c|c|}
\hline & \multicolumn{2}{|c|}{$\begin{array}{l}\text { Most advantaged } \\
(N=32)\end{array}$} & \multicolumn{2}{|c|}{ Advantaged $(N=53)$} & \multicolumn{2}{|c|}{$\begin{array}{l}\text { Disadvantaged } \\
(N=69)\end{array}$} & \multicolumn{2}{|c|}{$\begin{array}{l}\text { Most disadvantaged } \\
(N=31)\end{array}$} & \multicolumn{2}{|c|}{ Total $(N=185)$} \\
\hline & Mean & S.D. & Mean & S.D. & Mean & S.D. & Mean & S.D. & Mean & S.D. \\
\hline Test class size & 44.5 & 14.92 & 51 & 22.39 & 56 & 29.38 & 54 & 29.39 & 52 & 25.59 \\
\hline
\end{tabular}

Note: Figures in the table are rounded off.

Table 13

Teaching load of science teacher

\begin{tabular}{|c|c|c|c|c|c|c|c|c|c|c|}
\hline & \multicolumn{2}{|c|}{$\begin{array}{l}\text { Most advantaged } \\
(N=32)\end{array}$} & \multicolumn{2}{|c|}{ Advantaged $(N=53)$} & \multicolumn{2}{|c|}{$\begin{array}{l}\text { Disadvantaged } \\
(N=69)\end{array}$} & \multicolumn{2}{|c|}{$\begin{array}{l}\text { Most disadvantaged } \\
(N=31)\end{array}$} & \multicolumn{2}{|c|}{ Total $(N=185)$} \\
\hline & Mean & S.D. & Mean & S.D. & Mean & S.D. & Mean & S.D. & Mean & S.D. \\
\hline Teaching time & 25.50 & 15.61 & 24.12 & 15.82 & 21.28 & 14.55 & 22.17 & 15.61 & 22.97 & 15.25 \\
\hline Work time & 28.71 & 16.11 & 29.95 & 15.9 & 28.33 & 17.82 & 25.77 & 15.37 & 28.43 & 16.52 \\
\hline
\end{tabular}

Note: Teaching time relates to the number of hours spent teaching; work time relates to the number of hours spent on activities related to work.

Table 14

Dedication and perceptions of science teachers

\begin{tabular}{|c|c|c|c|c|c|c|c|c|c|c|}
\hline & \multicolumn{2}{|c|}{$\begin{array}{l}\text { Most advantaged } \\
(N=32)\end{array}$} & \multicolumn{2}{|c|}{ Advantaged $(N=53)$} & \multicolumn{2}{|c|}{$\begin{array}{l}\text { Disadvantaged } \\
(N=69)\end{array}$} & \multicolumn{2}{|c|}{$\begin{array}{l}\text { Most disadvantaged } \\
(N=31)\end{array}$} & \multicolumn{2}{|c|}{ Total $(N=185)$} \\
\hline & Mean & S.D. & Mean & S.D. & Mean & S.D. & Mean & S.D. & Mean & S.D. \\
\hline Lesson planning & 3.47 & .79 & 3.32 & .89 & 3.36 & .92 & 3.34 & .91 & 3.36 & .91 \\
\hline Teaching activities & 55.31 & 54.6 & 52.27 & 43.67 & 55.56 & 52.18 & 66.94 & 57.76 & 56.48 & 51.14 \\
\hline Appreciation & 2.44 & .72 & 2.20 & .52 & 2.35 & .64 & 2.13 & .43 & 2.28 & .595 \\
\hline
\end{tabular}

Note: Lesson planning refers to the lesson planning taking place outside school hours; teaching activities is the \% of time spent on teaching activities; appreciation refers to the perceptions for the community and the students for the teachers' work. 
Table 15

Teaching style of science teachers: frequency of pupils working in pairs or groups and teacher beliefs about student success and science

\begin{tabular}{|c|c|c|c|c|c|c|c|c|c|c|}
\hline & \multicolumn{2}{|c|}{$\begin{array}{l}\text { Most advantaged } \\
(N=32)\end{array}$} & \multicolumn{2}{|c|}{$\begin{array}{l}\text { Advantaged } \\
(N=53)\end{array}$} & \multicolumn{2}{|c|}{$\begin{array}{l}\text { Disadvantaged } \\
(N=69)\end{array}$} & \multicolumn{2}{|c|}{$\begin{array}{l}\text { Most disadvantaged } \\
(N=31)\end{array}$} & \multicolumn{2}{|c|}{ Total $(N=185)$} \\
\hline & Mean & S.D. & Mean & S.D. & Mean & S.D. & Mean & S.D. & Mean & S.D. \\
\hline Group work & 4.38 & .10 & 4.43 & 1.16 & 4.31 & 1.03 & 4.39 & 1.09 & 4.37 & 1.07 \\
\hline Beliefs-science & 18.48 & 2.84 & 19.56 & 2.79 & 19.26 & 2.55 & 19.16 & 2.11 & 19.19 & 2.61 \\
\hline Beliefs-student success & 14.50 & .88 & 14.48 & .87 & 14.43 & .88 & 14.42 & 1.84 & 14.45 & 1.09 \\
\hline
\end{tabular}

Note: Group work refers to the frequency of working in pairs or groups; beliefs-science refers to beliefs about science; beliefs about student success refers to beliefs about student success.

Table 16

Summary of relationships of classroom and teacher factors with science achievement

\begin{tabular}{|c|c|c|c|c|c|c|}
\hline \multirow[t]{2}{*}{ Factor } & \multirow[t]{2}{*}{ Item/scale } & \multicolumn{4}{|l|}{ Level of advantage } & \multirow{2}{*}{$\begin{array}{l}\text { Science score } \\
\text { (total sample) }\end{array}$} \\
\hline & & More advantaged & Advantaged & Disadvantaged & Most disadvantaged & \\
\hline Age & Age (young) & + & 0 & 0 & - & 0 \\
\hline Sex & Sex (female) & + & - & 0 & 0 & - \\
\hline \multirow[t]{5}{*}{ Qualifications } & Highest qualification (university) & + & 0 & 0 & + & + \\
\hline & Biology & 0 & + & 0 & + & 0 \\
\hline & Chemistry & 0 & 0 & 0 & 0 & 0 \\
\hline & Physics & 0 & 0 & 0 & + & 0 \\
\hline & Science Education & + & + & 0 & 0 & 0 \\
\hline Experience & No. of years & + & 0 & 0 & 0 & 0 \\
\hline Teachers' beliefs & Pupils' success & - & 0 & 0 & 0 & 0 \\
\hline \multirow[t]{2}{*}{ Teaching style } & Time on teaching activities & + & 0 & 0 & 0 & 0 \\
\hline & Group work & + & + & 0 & 0 & + \\
\hline \multirow[t]{2}{*}{ Teacher load } & Teaching time (more) & + & + & + & + & + \\
\hline & All time-work & + & 0 & + & 0 & + \\
\hline \multirow[t]{3}{*}{ Attitudes to teaching } & Appreciation (more) & + & + & + & 0 & + \\
\hline & Lesson plan (more time spent) & + & 0 & + & 0 & 0 \\
\hline & Nature of science & - & 0 & 0 & - & - \\
\hline \multirow[t]{2}{*}{ Limitations } & Teaching related & - & 0 & + & 0 & - \\
\hline & Pupil related & - & 0 & 0 & 0 & 0 \\
\hline Resources & Computers & + & + & + & 0 & + \\
\hline First language & Teacher Home language & + & + & + & + & + \\
\hline No. of 1st language pupils & Proportion pupils language & + & + & + & + & + \\
\hline Race & Race-teacher & + & + & + & + & + \\
\hline Location & Location & + & 0 & + & + & + \\
\hline Class size & Test class size (smaller) & - & - & 0 & 0 & 0 \\
\hline
\end{tabular}


Appendix A

Fig. A1.

INPUTS

PROCESSES

OUTPUTS

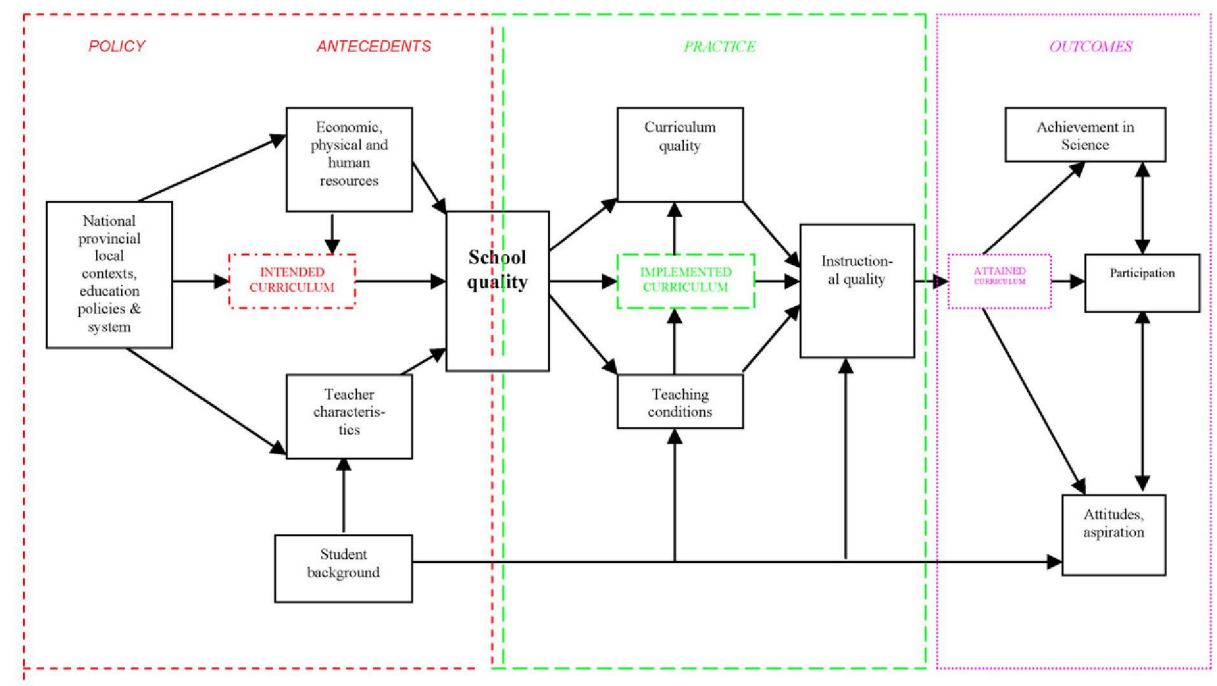

Fig. A1. Factors related to science achievement (adapted from Shavelson, McDonnell, \& Oakes, 1987)

\begin{tabular}{lcccc} 
Appendix B. Teachers' age, gender, language same as language of instruction, proportion of first language pupils in class \\
\hline & $\begin{array}{l}\text { Most advantaged } \\
(N=32)\end{array}$ & $\begin{array}{l}\text { Advantaged } \\
(N=53)\end{array}$ & $\begin{array}{l}\text { Disadvantaged } \\
(N=69)\end{array}$ & $\begin{array}{l}\text { Most disadvantaged } \\
(N=31)\end{array}$ \\
& 2.91 & 2.71 & 2.79 & 2.8 \\
$(N=185)$
\end{tabular}

${ }^{a}$ First language meaning that the home language was the same as the language of instruction.

Appendix C. Reliability analysis for classroom factors

\begin{tabular}{llc}
\hline Factor & Individual variable & Cronbach $\alpha$ science \\
\hline Teaching style & Class activities-higher order skills (four items) & .64 \\
& Class activities (three items) & - \\
\%of time spent on teaching activities (six items) & .86 \\
Teacher beliefs & Teachers' beliefs about students success (five items) & .61 \\
& Teachers' beliefs in general (six items) & .68 \\
Limitations & Obstacles to teachers' ability to teach-pupil related (seven items) & .69 \\
& Obstacles to teachers' ability to teach-teacher related (seven items) & .84 \\
\hline
\end{tabular}

Appendix D. Description of variables and correlations with the science score

\begin{tabular}{llc}
\hline Factor & Individual factor & Pcorr. science score \\
Teaching style & \% of time spent on teaching activities (6 items) & .092 \\
& Teaching methods and classroom organisation (two items) & $-.244^{* *}$ \\
Teacher load & Teaching time & $.388^{* *}$ \\
& All time spent on activities related to work & $.293^{* *}$ \\
Attitudes to teaching & Perception where society and pupils appreciates work of teacher & $.419^{* *}$
\end{tabular}


Appendix D (Continued)

\begin{tabular}{lll}
\hline Factor & Individual factor & Pcorr. science score \\
\hline \multirow{3}{*}{ Experience } & Teacher preparation outside school hours-lessons planning alone by teacher \\
Age & Number of years teaching & .092 \\
Sex & Age of the teacher & .062 \\
Qualifications & Gender of the teacher & .055 \\
& Highest level of qualification & $.223^{*}$ \\
& Specialisation in Biology & $-.213^{* *}$ \\
& Specialisation in Chemistry & $-.145^{*}$ \\
Experience & Specialisation in Physics & -.075 \\
Teachers' beliefs & Specialisation in Science Education \\
& Years of teaching & $-.204^{* * *}$ \\
Limitations & Teachers' belief about pupils' success \\
& Teachers beliefs about the nature of science \\
Resources & Obstacle to teachers' ability to teach-teaching related \\
First language & Obstacle to teachers' ability to teach-pupil related \\
Groups of first language pupils & Computers outside of classroom in school \\
Race & Home language of teacher same as the medium of instruction \\
Location & Proportion of pupils whose language is the same as the language of instruction \\
Class size & Race group of teacher & -.075 \\
\hline
\end{tabular}

* Significant at the 05 level.

- Highly significant at the .01 level.

Appendix E. Relationships between teacher characteristics, teaching conditions, resources and science achievement (correlations)

\begin{tabular}{|c|c|c|c|c|c|c|}
\hline \multirow[t]{2}{*}{ Factor } & \multirow[t]{2}{*}{ Item/scale } & \multicolumn{4}{|l|}{ Level of advantage } & \multirow{2}{*}{$\begin{array}{l}\text { Pcorr. science score } \\
\text { (total sample) }\end{array}$} \\
\hline & & More advantaged & Advantaged & Disadvantaged & Most disadvantaged & \\
\hline $\begin{array}{l}\text { Age } \\
\text { Sex }\end{array}$ & $\begin{array}{l}\text { Age } \\
\text { Sex }\end{array}$ & $\begin{array}{c}.238 \\
-.397^{*}\end{array}$ & $\begin{array}{l}-.107 \\
-.264\end{array}$ & $\begin{array}{r}.088 \\
-.126\end{array}$ & $\begin{array}{r}-.221 \\
.182\end{array}$ & $\begin{array}{c}.055 \\
-.164^{*}\end{array}$ \\
\hline Qualifications & $\begin{array}{l}\text { Highest qualification } \\
\text { Biology } \\
\text { Chemistry } \\
\text { Physics } \\
\text { Science Education }\end{array}$ & $\begin{array}{l}.401^{*} \\
.112 \\
.104 \\
.091 \\
.255\end{array}$ & $\begin{array}{l}.151 \\
.390^{* *} \\
-.030 \\
.124 \\
.249\end{array}$ & $\begin{array}{l}.074 \\
.141 \\
.056 \\
.121 \\
.167\end{array}$ & $\begin{array}{l}.359^{*} \\
.361^{*} \\
.096 \\
.331 \\
.091\end{array}$ & $\begin{array}{l}.223^{*} \\
.213^{* *} \\
.145^{*} \\
.075 \\
.204^{* *}\end{array}$ \\
\hline $\begin{array}{l}\text { Experience } \\
\text { Teachers' beliefs }\end{array}$ & $\begin{array}{l}\text { No. of years } \\
\text { Pupils' success }\end{array}$ & $\begin{array}{r}.242 \\
-.229\end{array}$ & $\begin{array}{l}-.159 \\
-.131\end{array}$ & $\begin{array}{r}.128 \\
-.101\end{array}$ & $\begin{array}{r}-.142 \\
.057\end{array}$ & -.075 \\
\hline Teaching style & $\begin{array}{l}\text { Time on teaching activities } \\
\text { Group work }\end{array}$ & $\begin{array}{l}-.425^{*} \\
-.468^{* *}\end{array}$ & $\begin{array}{l}-.155 \\
-.329^{*}\end{array}$ & $\begin{array}{r}.042 \\
-.153\end{array}$ & $\begin{array}{l}-.137 \\
-.079\end{array}$ & $\begin{array}{l}.092 \\
-.244^{* *}\end{array}$ \\
\hline Teacher load & $\begin{array}{l}\text { Teaching time } \\
\text { All time-work }\end{array}$ & $\begin{array}{l}.417^{*} \\
.526^{* *}\end{array}$ & $\begin{array}{l}.372^{* *} \\
.189\end{array}$ & $\begin{array}{l}.348^{* * *} \\
.355^{* * *}\end{array}$ & $\begin{array}{l}.508^{* * *} \\
-.056\end{array}$ & $\begin{array}{l}.388^{* * *} \\
.293^{* * *}\end{array}$ \\
\hline Attitudes to teaching & $\begin{array}{l}\text { Appreciation } \\
\text { Lesson plan } \\
\text { Nature of science }\end{array}$ & $\begin{array}{l}.324 \\
.236 \\
-.676^{* *}\end{array}$ & $\begin{array}{r}.404 \\
-.126 \\
-.096\end{array}$ & $\begin{array}{l}.557^{* *} \\
.219 \\
-.175\end{array}$ & $\begin{array}{r}.083 \\
-.114 \\
-.268\end{array}$ & $\begin{array}{l}.419^{* *} \\
.092 \\
-.298^{* *}\end{array}$ \\
\hline Limitations & $\begin{array}{l}\text { Teaching related } \\
\text { Pupil related }\end{array}$ & $\begin{array}{l}-.574^{* *} \\
-.349\end{array}$ & $\begin{array}{r}-.146 \\
.167\end{array}$ & $\begin{array}{l}-.218 \\
-.039\end{array}$ & $\begin{array}{l}.094 \\
.67\end{array}$ & $\begin{array}{l}-.309^{* *} \\
-.040\end{array}$ \\
\hline Resources & Computers & .292 & .234 & $.416^{* *}$ & -.166 & $.300^{* *}$ \\
\hline First language & Teacher home language & $.901^{* *}$ & $.670^{* * *}$ & $.772^{* *}$ & $.753^{* * *}$ & $.746^{* * *}$ \\
\hline Groups of first language pupils & Proportion pupils language & $.895^{* *}$ & $.685^{* *}$ & $.804^{* *}$ & $.842^{* *}$ & $.781^{* *}$ \\
\hline Race & Race-teacher & $.773^{* *}$ & $.822^{* * *}$ & $.792^{* * *}$ & $.774^{* * *}$ & $.790^{* 0 *}$ \\
\hline Location & Location & $.598^{* *}$ & .184 & $.464^{* *}$ & $.453^{*}$ & $.448^{* *}$ \\
\hline Class size & Test class & $-.373^{*}$ & $-.305^{*}$ & -.046 & -.121 & $-.196^{* *}$ \\
\hline
\end{tabular}

